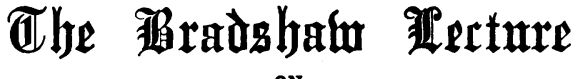 \\ ON
}

\section{THE RESULTS OF BRONCHIAL OBSTRUCTION.}

Delivered before the Royal College of Paysicians OF LONDON ON NOVEMBER 18T, 1910.

By G. NeWTON PITT, M.D.Cantab., F.R.C.P.LoND.,

HYSICIAN TO GUY'S HOSPITAL AND LECTURER ON MEDICINE.

\section{[With Special Plates.]}

Mr. President and Gentlemen,-My first daty is to thank your predecessor in the chair for the honour he has done me in nominating me for this lectureship to-day, and to express the diffidence I feel in choosing a subject on which it may seem there is not much that is new to be said.

We are met to-day to do honour to the memory of Dr. William Wood Bradshaw, who, it would appear, was a man of wide interes' $s$ he contributed papers on such subjects as the use of cod-liver oil in chronic rheumatism, on narcotics, on abdominal abscess, and other non. professional articles to the Miscellany and elsewhere. Born in 1801 at Bristol, according both to Foster's Alumni Oxoniensis and to the inscription on his grave, he was educated at the Westminster and Mid. dlesex Hospitals, taking his M.R.C.S. in 1833 . In the early part of the same year he became M.D.Erlangen. He becamo an Extra Licen. tiate of this College in 1841, after examination by the President and the "Elects," which entitled him to practise beyond seven miles from London. In 1854 he was elected a Fellow of the Royal College of Sur. geons of England. In 1859 Dr. Coplans Hawkins and Dr. R. P. Smith nominated him as a Member of this College, which nomination was ipproved. At the mature age of 43 he

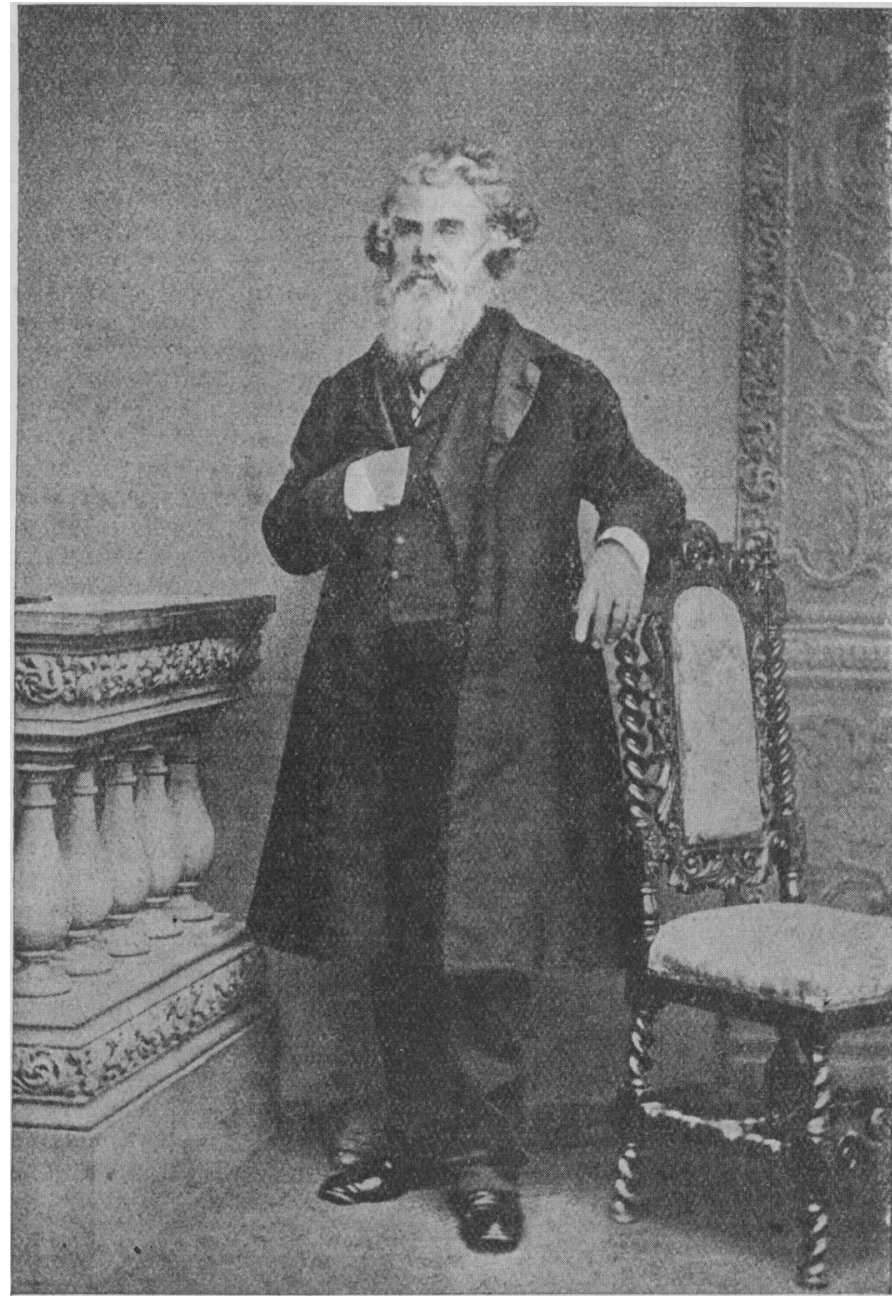

Dr. WHLlaM WOOd Bradbhaw.

1. The lung may be sligbtly reduced in size. There may be definite diminution in the entry of air, but the resonance may be unaltered, and even post morlem beyond an increase in the amount of mucoid contents, and a diminution in the amount of air in the lung, this may be all that can be observed, even when there has been definite pressure on the tabe.

2. The chest may be hyper-resonant, the lung overdistended, and the diaphragm displaced down abnormally. This occurs only with partial obstruction of the tabe when respiration is vigoroue, and will be discussed under the results produced by aneurysm.

3. The lang may be reduced in size, airless and anlid from collapse. Th 9 chest will be dull on percussion. This results when the obstruction to the tabe is complete, or when respiration is feeble. It may occur within a few hours, and was studied by Lichtheim by observing the effects of introducing foreign bodies into the bronchi so as to completely block them, but practically complete obstruction is generally due to other causes, and rarely to the presence of a foreign body. In the early stage the bronchi beyond the obstruction are empty. The langs in the first and second conditions also tend gra. dually to become more or less airless.

4. The bronchi become filled with retained secre. tions, at first chiefly mucus, but catarrhal changes soon ensue and cells accumulate, with puralent and inflam. matory products as well.

5. Secondary inflam. matory changes take place, due partly to the entry of secretions into the alveoli, so that what has been called a retention pneumonia ensues; the alveoli fill with catarrbal cells and giant cells appear, although they are unconnected with tubercle, as has been shown by inoculating animals with the products. When alveolar walls remain long in contact, organizution with obliteration takes place and now connective tissue is formed. The bronchi normally often contain a fow staphylooocci and streptococci, which when retained in suitable media begin to develor, with the result

Hall, Oxford, and was granted a degree in 1847 without any examination. He married the widow of a wealthy jeweller at Andover, and, according to $\mathrm{Mr}$. Rickman Godlee, to whom I am indebted for his portrait and for much of this information, her money was to be left away in case she remarried; but they bought the reversion, married, and settled down at Reading. He seems to have been a cultivated, refined, somewhat eccentric man with a rather theatrical manner, and never did much practice. He died in 1866; his widow founded a lectureship at each of the Culleges in order to perpetuate his memory.

The Resucts of Compression of a Bronchus. The results of compression of a brinchus may be the following: that pyrexia and a more or less acute pneumonic change develops.

The changes that have taken place so far may all pass away and leave but little damage ; but two further changes soon take place-a general fibrosis of the lung beyond the obstruction and a bronchiectasis. These ultimately develop, whatever be the initial process, if the obstruction persist.

6. Dilatation of the tabes. This does not take place equally in all the tubes obstructed, and its distribution is largely determined by local causes. When only one branch of a bronchus has been pressed upon, the dilata. tion is limited to the tubes in its area. Generally the tabes at the posterior and lower part of the long are the most affected, probably because the secretion tends to stagnate there, and set up loral destric- 
tive changes, as the patient is in the semirecumbent position.

Normally there is a constant secretion of mucus in the bronchi, which passes imperceptibly out into the larger tabes and thence to the trachea, bat we are quite ignorant what is the amount normally secreted in twenty-four hours. When a bronchus is occluded the mucus at once begins to accumulate, and is capable of being secreted under pressure, so that as with an obstructed gall bladder the tabes become over.distended. Now bronchiel contents cannot pass through the bronchial wail on account of the basement membrane; they can only pass out by the bronchas, or be sucked back by inspiration into the alveoli which remain patent, and so on into the lymphatics and the glands. Normally the contents pass almost entirely by the bronchus, because the initial act of expiration consists in the contraction of the lung by its own elasticity, which as the alveoli empty drives the secretion out of the smaller bronchioles into the larger tabes, to be then carried on by the forcible muscular expiration. With a collapsed lung this initial mechanism fails. As the alveoli become blocked, there is a greater suction on those that remain, and this leads to further ocolusion of the alreoli, but the morement of the chest on the affected side is always more or less feeble. The result is that, whether the lung is distended or collepsed, the bronchi become distended with mucoid or mucoparulent contents under high pressure, and hence the walls yield. Owing to the interference with the circulation, which is largely dependent on the suction of the elveoli as they open up with inspiration, the arteries being on the proximal and the veins on the distal side, the tissues are insufficiently nourished, and this, added to the local irrita. tion, causes the bronchial walls to deteriorate, so that the elastic and muscle fibres tend to disappear and local dilatations occar.

It is an old controversy as to whether inspiratory or expiratory efforts are the more efficient in the production of bronchiectases, and I am sorry to say that at the present day the latter theory seems to have the more advocates. In the cases under consideration it is difficult to see how violent expiration, compressing the lung forcibly, as with a cough, can throw any greater strain on the inside of the bronchi than it does on the outside. If the same pressure is applied all round the wall of a bronchus it cannot tend to dilate it. The increased pressure of the contained air is the result of the pressure applied to the outer surface of the bronchus. On the other hand, if it is borne in mind that aspiration is applied to the surface of the lung by inspiration, which tends to open it up, and if the alveoli fail to respond, strain is thrown on the deeper parts, such as the bronchi; if there is no obstruction, they open np and fill with air from the trachea, bat when the bronchus is obstructed they must be subjected to strain which tends to dilate them. The feebleness of the respiratory movements spares them greatly, but the contracted condition of the lung tends to set up an inspiratory dyspnoea, and paroxysms occur from time to time, especially with exertion, which must aspirate the tubes and gradually make them dilate.

Consequently we do not find marked dilatation except when there is also in these cases definite fibrosig. The slighter degrees of dilatation are associated with but slight consolidation of the lung. The presence of pleuritic effasion usually inhibits, or entirely prevents, the dilatation of the bronchi, because the lung, not being in contact with the pleura, is no longer held up by capillary attraction between the two surfaces, and therefore is not subjected to so much aspiration. There is no evidence that connpctive tissue in contracting is capable of producing traction on the tubes at all comparable with that exercised by the powerfal suction action of inspiration. It was noted many years ago by Dr. Charlton Bastian that in onefifth of all cases of cirrhosis of the lung the tabes are not at all dilated. This is what might naturally be expected, as respiration would probably be feeble in many, bat if the fibroid change were the essential causo of bronchiectasis it would be inexplicable.

It has been suggested that the accumulated weight of the contained secretions will suffice to distend the terminal tubes when a bronchus is compressed by an aneurysm. The terminal tubules are not the ones that are especially dilated, and the tabules lie in a closed box, the chest, and are supported outside by the same pressure as that inside them. The pressure inside the chest may be slightly increased, but there is no difference between the pressures inside and outside the bronchi, which is the important factor. The essential factors which lead to dilatation of the tubes would therefore appear to be local changes in the walls, the accumulation of secretion ander tension, and the effects of inspiration on a lang which is not capable of expanding satisfactorily.

7. Fibroid thickening of the lung. There are several factors which condace to this result: inflammatory and organizing connective tissue changes result $(a)$ from the retention of the secretions, $(b)$ from the prolonged collapse of the alveoli, (c) from the broncho. pneamonia, (d) from the peribronchial changes which follow on the destruction of the bronchial epithelium, which generally takes places, and finally $(e)$ from the interference with the palmonary and lymphatio circulations which normally depend on the opening up and the contraction of the alveoli. Moreover, when we bear in mind that in health the alveolar surface of each lung amounts to 100 square metres, each air cell being bathed in a film of blood $10 \mu$ in thickness, we can realize what a difference it must make to the nutrition of the tissues when the alveoli fail to open and the amount of the circulating blood is enormously redaced; hence retrograde fibroid changes must gradually develop. The fibroid change is therefore also. a natural sequence of obstruction, but the canses are not quite the same as those which produce the bronchiectasis.

8. Secondary infections producing a septic pneumonia breaking down into abscesses are not infrequent, and vary with the cause; in some they are essential and early, in others a late and accidental development.

9. Gangrene. This especially occurs with malignant disesse and when the pulmonary artery is occluded. The communication between the bronchial and pulmonary arteries is a free one, but varies in different cases, and hence gangrene does not always occur even when the palmonary artery is compressed. The condition may also. resalt from a very virulent infection.

10. Putrefactive changes. Although the bronchi areoften dilated, the contents are not always foul. The change is always a serious one, as it accelerates the destructive changes in the lung and introduces a severe toxic poison into the system; the organisms are usually anaërobic, and hence are but rarely cultivated.

11. As a secondary result of the bronchiectasis, especially if foul, there may be a plearisy or an empyema.

Although stridor is a symptom that at once attracts attention, it is to be noted that it was present in but a very small proportion of the cases examined; it is marked when the trachea is involved, bat otherwise was. noticeable in only two or three of the cases of growth and aveurysm, yet severe dyspnoes was common.

Causes of Bronchial Obstruction.

Bronchial obstruction may arise from causes without or within the bronchus. Usually only one bronchus is affected, but in some cases the tracher is involved, as well as one or both bronchi. The external causes producing compression are :

1. Aneurysm of the aorta (35)

2. Malignant disease (56) of :

(a) Oesophagus, epithelioma (16) ;

(b) Bronchial glands-(1) primary, usually sarcoma (26); (2) secondary to growth at a distance (6).

3. Enlarged caseous or suppurating glands (12).

4. Gummata (2)

5. Abscese (3)

6. Dilated left auricle (1).

The internal causes are :

1. Bronchiolitis.

2. Syphilitic ulceration with scarring (5)

3. Primary malignant disease of a bronchus (usually columnar-celled carcinoma) (8).

4. Foreign bodies in the bronchus (8).

The material I propose to discuss is collected from our records at Guy's Hospital, and I desire to thank my colleagues for their kind permission to refer to cases under their care. I shall only discuss the general results and give a few illustrative cases. 
Anedrysm of the Aorta.

Daring the period taken, out of 11,000 post-mortem examinations there have been 140 aneurysms of the thoracic aorta. Thirty compressed the lett bronchus, and 16 of these eroded into it; 5 compressed the right bronchus and none eroded it. To contrast the results of compression produced by the various causes it may be noted that in this series, in 16 cases-that is, one-half-there was bronchiectasis beyond the obstruction, but in only 8 was it associated with a marked fibroid thickening of the connective tissue and increased pigmentation of the lung with a thickened pleura. In several (6) there was also an acute terminal pneumonia, and in 4 an acute septic pneumonia; in 3 there was an acute gangrene, and sometimes there was an acute pleurisy, but only once was there a pleuritic effusion. When there was no definite dilatation of the tubes the langs generally showed bronchi full of muco-purulent secretion, often with collapse and a more or less airless lung.

The dilatation of the tubes takes place only in the part of the lang beyond the obstruction, and is irregularly dis. tributed, being generally least marked in the anterior part. The amount varies greatly; in some cases the distension of the tubes is but slight, when the lung may be also collapsed or pneumonic. Marked increase in the fibrous tissue, as it occurs less frequently, appears to be to some extent a secondary change, and to be partly set up by the absorp. tion of the irritating contents. In advanced cases the fibrous trabeculae stand out, the lang is very tough, and may bo ridaled with intercommunicating cavities. In only one in twelve was an acute gangrenous condition noted, although in many the contents were very foul. The bronchiectasis requires at least two or three months in which to develop, bat occasionally it took a year or more, and it is very remarkable how very latent the constitational symptoms may be so long as the changes are limited to the fibroid lung beyond the obstruction. When much foul secretion is expectorated, the healthy part of the lung is apt to become infected, and if an acute septic pneamonia develop, the disturbance to health is intense.

The ascending arch is not in very close relationship with the right bronchus, and only occasionally will an aneurysm of this part (usually a saccular one) compress the bronchus, and then on its anterior surface; not infrequently it will also involve the trachea; in none of the cases did it rupture into the bronchus. Occasionally the azygos vein, which is in close relation to the right bronchas, may also be compressed, and this may bo the explanation of the only case with plearitic effusion. In none of the right. sided cases did the breath sounds entirely disappear, nor did a local bronchiectasis develop.

A sac conneoted with the latter part of the transverse arch may compress more or less completely the left bronchus on its outer and anterior surface, and often the trachea as well, and very rarely the left pulmonary artery which lies above the bronchus (Fig. 1). This arterial stenosis probably accelerates retrograde changes in the lung and the development of the fibroid thickening, but it did not in any case lead to gangrene. In no case did an infarct form, and in only one did an anearysm rupture into the pulmonary artery. When the aneurysm comes off lower down it will compress the bronchus from behind and on its outer side (Fig. 2).

Sometimes, however, before the bronchas is completely occluded, the lung will become over.distended, there will be a hyper.resonant note, and the distended lung may displace the heart and push down the diaphragm. That this condition may result has been almost entirely overlooked by anthors, and no reference is made to it in the textbooks. Yet over-distension, we know, not infrequently cesults if the respiration is vigorous, when there is laryngeal obstruction in diphtheria, in tracheal obstruc. tion from an enlarged thyroid, thymus, or aneurysm, in asthms with spasm and therefore, with stenosis of the smaller bronchi, and in acute bronchitis and bronchiolitis.

It is also what we might expect. With inspiration the chest expands and the surface of the lung closely attached to it by capillary action follows and the air is sucked past the obstruction as the lung attempts to open. With expiration there is a contraction of the lang, due to its elasticity, which is feeble, but sufficient for ordinary parposes. This drives the air from the smaller to the larger bronchi, because the pressure in the former is the greater. When forcible expiration is applied, the bronchi as well as the lung tissue are compressed with an equal pressure; if there is no obstruction the air passes on, and the pressure therefore falls in the larger bronchi. When an obstruction exists, however, this mechanism fails, the air has greater difficalty in escaping than it had in entering, and the lung becomes over-distended. The pressure may be so much raised that the diaphragm may be displaced two inches and the heart pushed out of position.

This condition gradually develops and persists for a certain time, but by degrees the bronchi fill with secretion, thus increasing the difficulties of the ingress of air, and as the contained air is not replaced, and is subjected to high pressure, it becomes absorbed by the pulmonary blood, while the lung becomes solid, airless, and dull on percussion. Lichtheim has shown experimentally that when the bronchus is completely occluded this airless condition develops almost at once.

In six of the cases the symptoms were so suggestive of pneumothorax that this diagnosis was more than once suggested.

This possibility of over-distension as a result of bronchial obstruction has been so far overlooked by all authors that the only definite recognition of the condition I have noted, is by the late Dr. Pearson Irvine, who, in the Pathological Transactions for 1878, recorded a case of aneurysm pressing on a bronchus in which the lang was larger than normal, although fibroid and bronchiectasic; he came to the conclusion that the result of the pressure had been first to over.distend the lung, that then the secretion had accumulated in the bronchi, and the air had been absorbed, while fibrosis and bronchiectasis from the greatly increased tension had compressed the blood ressels and impaired the nutrition of the tissues. C. Jacobsohn has also more than once noted that the position of the dullness set up by a growth at the root of the lung may vary with respiration owing to the over-distension of the affected lung, which is best shown by the $x$ rays.

CASE I.-Saccular Thoracic Aneurysm Compressing the Left Bronchus and Producing an Over-distended Lung.

By some it was thought that the case was one of pneumothorax. The patient was a man, aged 29 years, admitted in November, 1905. He had been in the army and had had syphilis. Cough had been present for a year, and had been worse for the last three months, with dyspnoes and pain in the left chest. He had no great distress while in bed; the left chest moved badly; there was no tactile vocel fremitus, and no voice nor breath sounds on the left side. On percussion the note was hyper-resonant. There was no cardiac dullness on the left, and on the right there was dullness, which varied with respiration, extending from the fourth rib out to beyond the right nipple and down to the liver. There was marked epigastric pulsation, the heart sounds were faint, and no brait was audible. There was compensatory breathing over the right chest. There was considerable uncertainty with regard to the diagnosis, but. it was thought that most probably the condition was due to an aneurysm pressing on the left bronchus. The patient was examined with the $x$ rays. The whole of the left side of the chest was remarkably transparent compared with the right; no foreign body was visible; the heart was displaced nearly $2 \mathrm{in}$. to the right of the sternum with deep inspiration, and back again behind the sternum with expiration. The diaphragm was depressed on the left side, but no trace of any aneurysm could be seen (Fig. 3). The temperature was normal and the palse 72. There were no stridor, no evidence of any syphilitic ulceration of the trachea and bronchi, and no expectoration. It was elicited that three months previously a crust of bread had gone "the wrong way," but had this passed into the bronchus there would have been evidence before now of septic pneumonia. The extreme translncency and distension of the left chest, with the absence of any change in the aorta, threw a doubt on the diagnosis of aneurysm, and it was thought that a possible explanstion of such marked translucency might be a pneumothorax, although no bruitd'airain could be elicited, and there was no evidence on the screen of a lung compressed by air. The left axilla was explored with a Southey's tube, but no air escaped. The resalt of this exploration was to produce an acute attack of pleurisy, and he felt very ill for some time. His temperature two days afterwards was $99^{\circ} \mathrm{F}$., and on the next day $101.6^{\circ}$, with a pulse of 112 and intense pain. The temperature did not reach the normal again for nine days.

In December the patient was tested with tuberculin with a negative result. Later his opsonic index to tubercle, was 0.38 . As the condition still remained obscure, the chest was again explored in December, with a negative result, except that there was again a sharp attack of pleurisy with pyrexia which lasted for ten days, when the condition again quieted down.' At 
the end of 1906 there was an impairment of resonance developing at the left base; there were still an absence of airentry, diminished tactile vocal fremitus and voice sounds. He now developed pain with sweating at night, cough, and expectoration, and at the apex behind there were distant breath sounds. A somewhat tympanitic note was noticed near the cardias area. No tubercle bacilli could be found. During the next month or two he had a large amonnt of muco-purulent expectoration which was not foul. In February he began to develop slight clubbing of the fingers, and a rub was andible over the left chest. On February 27 th he bad a rigor with a temperature of $105^{\circ}$ and a leucocytosis of 33,700 . He had a sharp attack of pleurisy lasting for ten days. In March the impulse of the heart had returned to the left si ie of the steraum. There were consonating râles at the back of the left lung snd not much difference between the note on the two sides.

It was at first difficult to explain the attacks of severe pleurisy which followed both attempts at exploration. It was clear afterwards that infcctive fluid from the distended bronchi had inoculated the pleura, as, doubtless owing to the great pressure under which it was retained, some lesked into the pleura from the puncture. Had the lung not been under tension it would probably not have set up any infection. The obstraction to the bronchus was not complete, as there was expectoration, although the movement was so feeble that we could not hear air being sucked up to the surface of the lung. It is noticesble that so long as the lung remained quiet, and before it became fibroid, mained in the lung, or were expectorated, the patient remained free from fever, yet the faintest trace in the plears set np a violent reaction.

His symptoms gradually quieted down, and he continued fairly well. I did not see him from April, 1906, to the end of February, 1907 whon he was seized with general pains, pyrexia, and troublesome cough. Soon the expectoration becsme abunextremely foul, so dant and vomited frequently. that he vomited frequently. On readmission he was very ill and feeble. The left chest was contracted; the move ment was deflcient, there was an impaired note at the apex and bolow, and it was also dull in the axilla. Over the upper spaces the entry was deficient and broncho-vesicular; below it was lost. Numerous râles were audible, with compensatory breathing on the right side. The pulee was irregular, 108; the impulse was dragged 3 in. outside the nipple by contraction side the nipple by contraction of the lung. A diagnosis of gangrene of the lung was fatal on the $26 t h$, three days after admission.

Post mortem a saccular aneurysm opening just at the commencement of the descending sorta had compressed the left bronchus und produced a condition of flbrosis of the whole of the lef lung with recent septic bronchopneumonia (Fig. 4). Ther was bronchiectasis of the tubes bejond the compression, with cavitation due to recent putrefactive infection, which wa most marked in the posterior part of the lower lobe (Fig. 5).

Until I saw this case I was quite unaware that a partial compression of a bronchus was capable of producing an orer-distended lung, which might be confused with pneumothorax.

CasE II.-The over-distension of a lung when there is pressure on the trachea, together with urgent dyspnoes, is well shown in Fig. 6. The patient was a man who was admitted with bronehitis and intense dyepnoes which sojn proved fatal. The trachea was found to be compressed by an anearysm of the transperse aorta.

The lang was enormously over.distended and had rup. tured, producing interlobular emphysema, as shown by the lines of the interlobalar septa, which, when fresh, were distended with air, but now are collapsed and empty.

I sm indebted to Dr. E. W. Martin for the two following akiagrams, which excellently illastrate my contention. Fig. 7 represents a chest taken from the back. The left side is uniformly transparent; the intercostal spaces ace wider than on the right. The diaphragm is flattened and displased downwards and the heart to the right. The aneurysmal dilatation of the arch, with the marked excursion of pulsation, is well shown. There were well.marked signs of an aneurysm compressing the left bronchus. The condition was diagnosed on account of the skiagram as pneumothorax with aneurysm, but the appearance is really due to an over-distended lung. This will be at once apparent if we contrast it with an equally good skiagram of a pneumothorax (Fig. 8), also taken so long ago as 1902 by him. Here the air space is more trans. parent than was the over-distended lung, but the lung, shrunk up near its root, is obvious; this was wanting in the other picture. The heart and diaphragm are more displaced, and the latter has a much sharper outline.

[Since the lecture Dr. Martin has been able to find me the following notes of this case, which was in Victoria Park Hospital in 1902 :

There was pulsation over the upper part of the sternum with $a$. dull note. The note over the left chest was resonant, no cardiac dullness, the apex beat was 1 in. to the left of the sternum in the fifth space, the heart sounds were very feeble, but best heard on the right of the sternum; extremely feeble breath sounds all over the left chest-it hardly moves at all-and the whole chest, both back and front is larger than the right. An exploring syringe was introduced in the seventh space posteriorly on the left side, and connected with a. tube under water, when about thirty bubbles of air escesped.

The condition at that time was considered to be one of pneumothorax with aneurysm. The escape of the bubbles of air naturally suggested this; the skiagram, bowever, is definitely that of an over.distended Jung, and I am supported in this view by Dr. Hugh Walsham. The air must, therefore, have escaped from the interior of the lung itself, and the explanation is that it must have been retained under great pressure, which is also indicated by the condition of the lungs.]

C.ASE III. - Aneurysm Compressing the Left Bronchus signs at one time suggesting rneumothorax.

The patient was a man, aged 39 years. In Ootober 1906, there was pain behind the sternum. The physical signs on admission left it doubtful whether he had pneumothorax or an obstruction of the left bronchus. There were cough and stridor, there was deflcient movement of the left side, but it looked enlarged. Some hyper-resonance was present. There were no tactile vocal fremitus, and no breath sounds, and voice counds were diminished; on the right side there was compensatory breathing. The heart sounds were not well heard on the left side, but were better than normal on the right side. On December 15th a skiagcam showed slightly increased opacity in the region of the aorta. On January 7 th there was no dullness; no breath sounds were audible over the left chest. In February breathing was audible behind in the upper part, but the cardiac impulse was not palpable. In March there was a better entry of air into the left lung, with a few râles. The impulse was in the sixth space one inch outside the nipple. On March 14th the left base was becoming dull ; when the patient went out in May the left chest bad an im. paired note with deficient breath sounds. Fatal haemoptysis occurred a few weeks later.

CASE IV.-Saccular Aneurysm Compressing and Eroding the Left Bronchus: High-pitched Note over the Left Chest: Signs suggestive of Pneumothorax: Fibrosis with Bronchiectasis.

The patient, a man aged 38 years, had had cough and pain in the chest for six months. The left chest was less flattened than the right, there was defective movement, and a highpitched note all over on the left side. There was no cardiac dullness and no dullness in the axilla. Voice sounds were deficient and breath sounds absent. Behind, the left chest 
DR. NEWTON PITT ON THE RESULTS OF BRONCHIAL OBSTRUCTION.

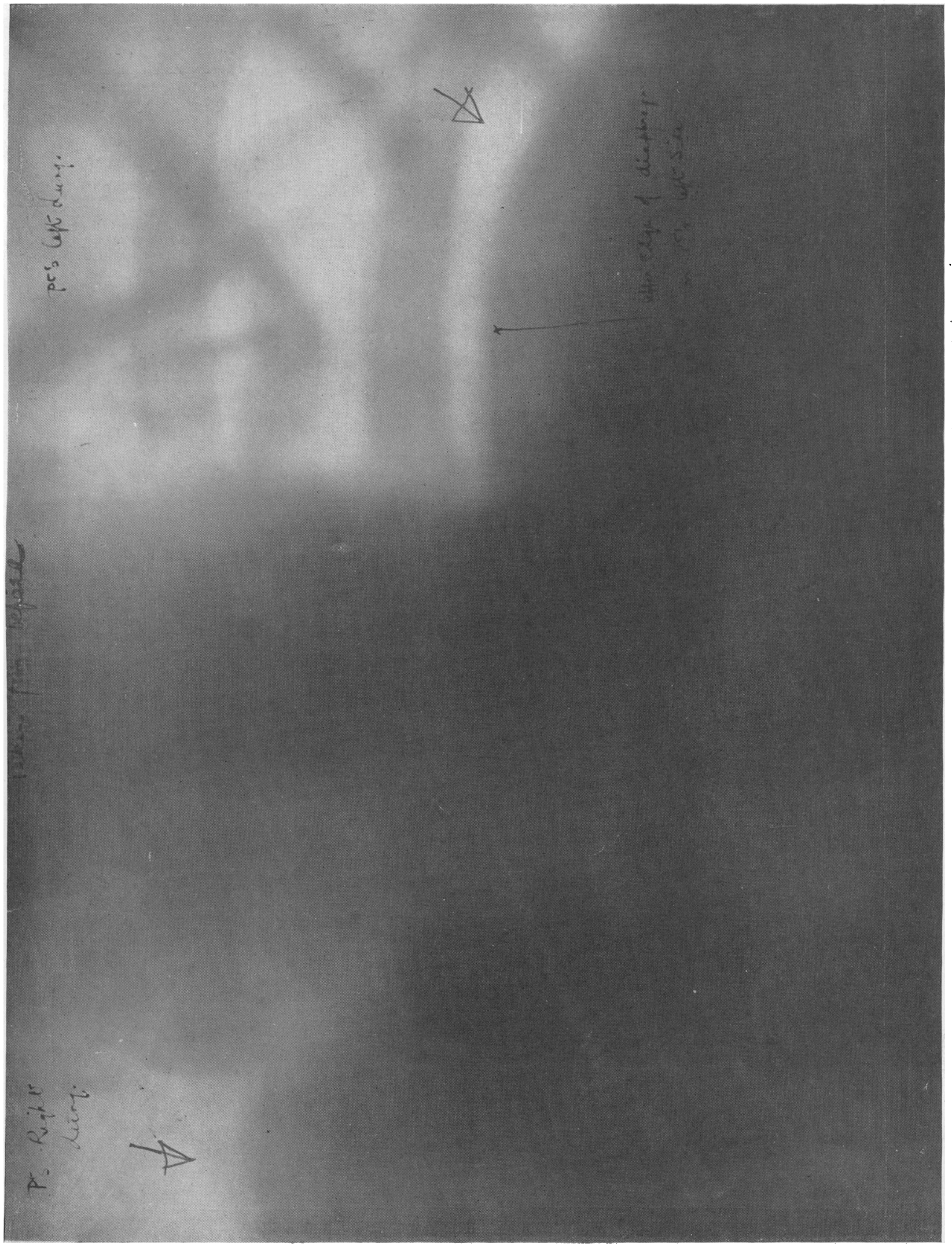


DR. NEWTON PITT ON THE RESULTS OF BRONCHIAL OBSTRUCTION.
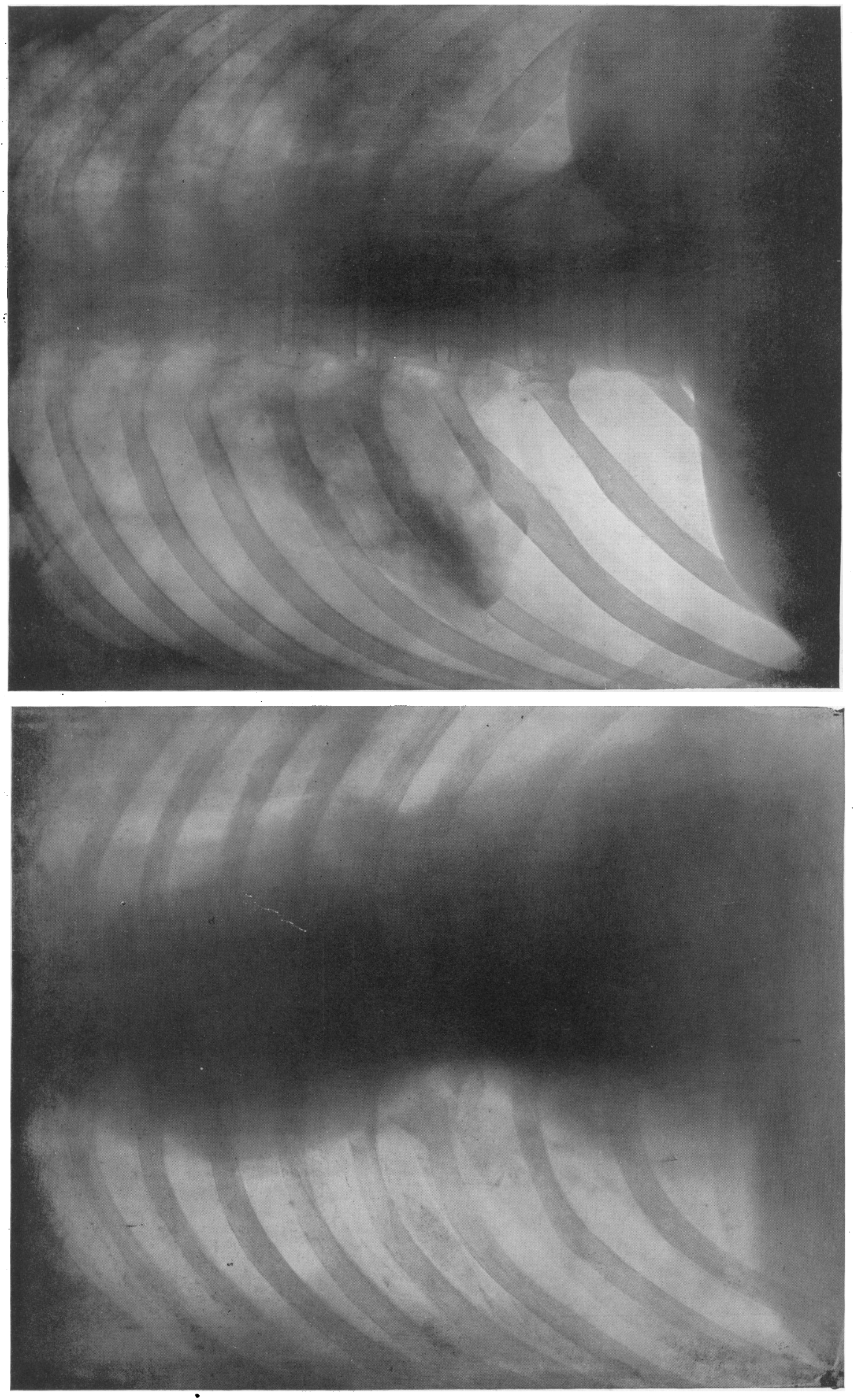
DR. NEWTON PITT ON THE RESULTS OF BRONCHIAL OBSTRUCTION.

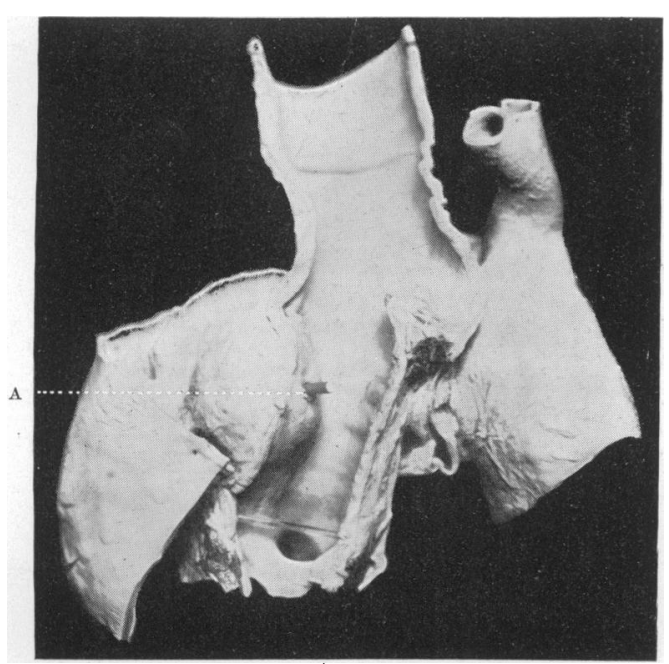

Fig. 1.

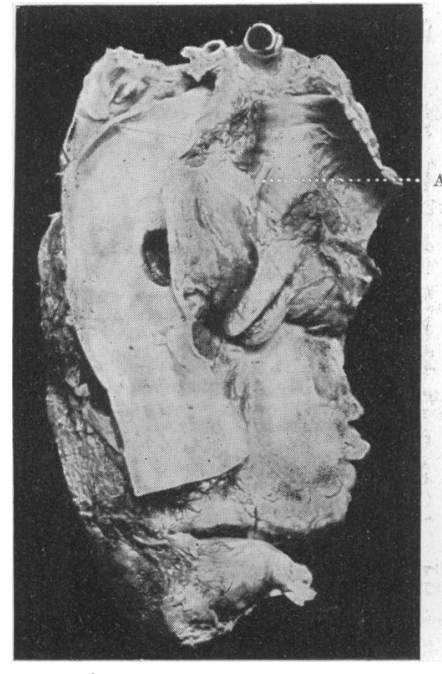

Fig. 4.

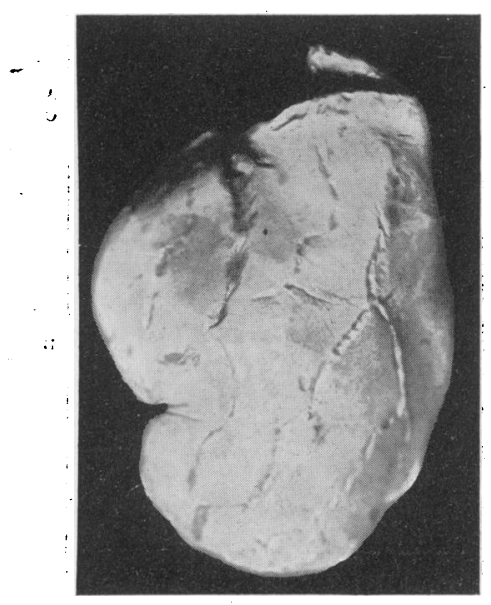

FIg. 6.

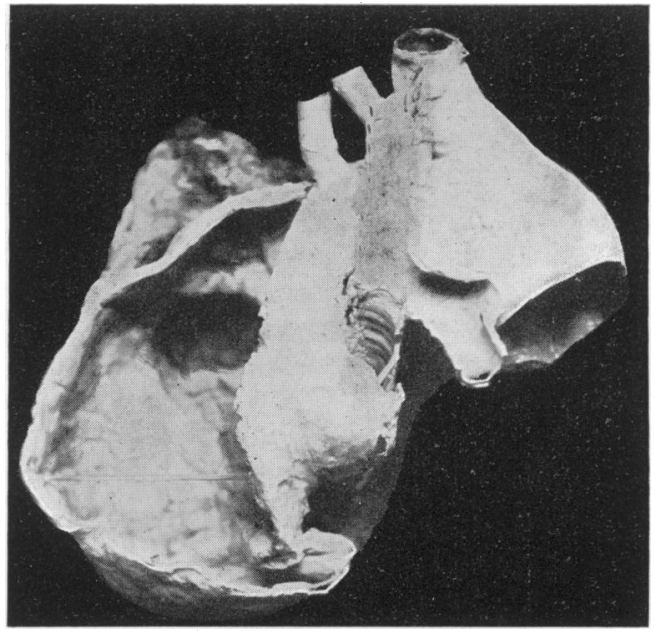

Fig. 2.

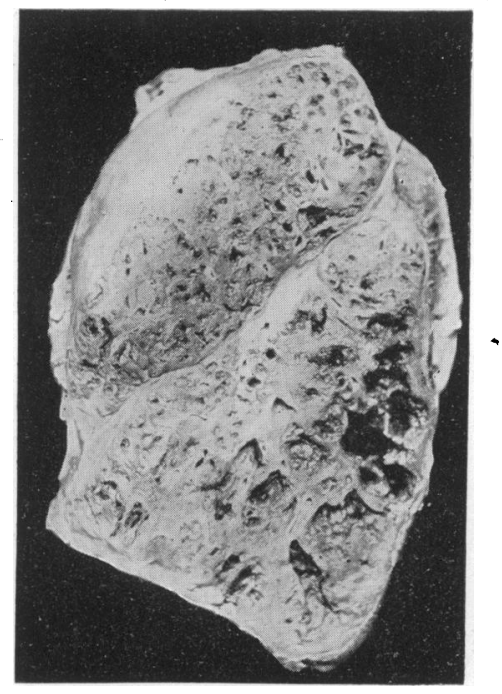

Fig. 5.

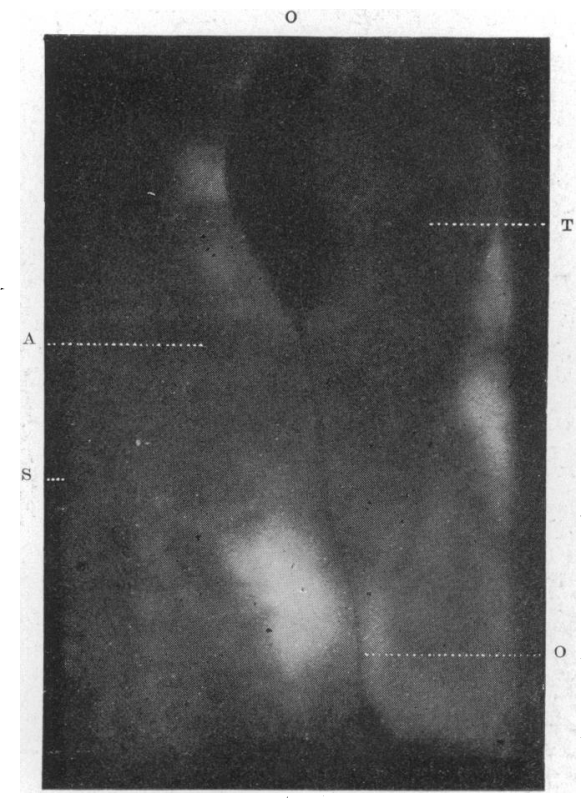

Flg. 9.

For description of figures see pp. 1848 and 1849. 
DR. NEWTON PITT ON THE RESULTS OF BRONCHIAL OBSTRUCTION.

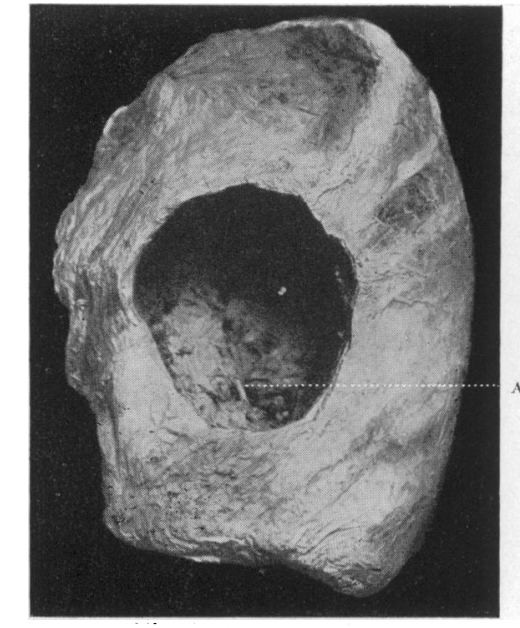

FIg. 10.

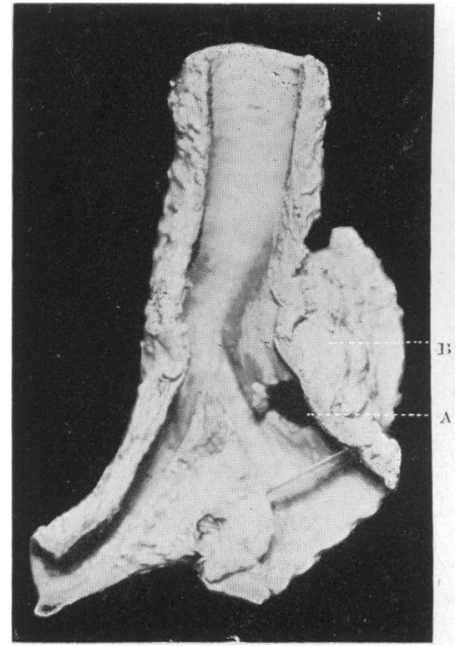

Fig. 12.

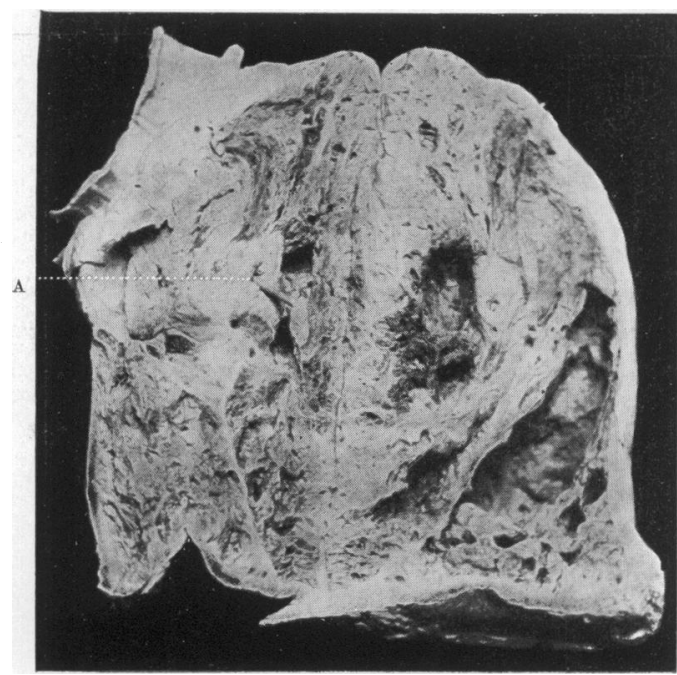

Fig. 11.
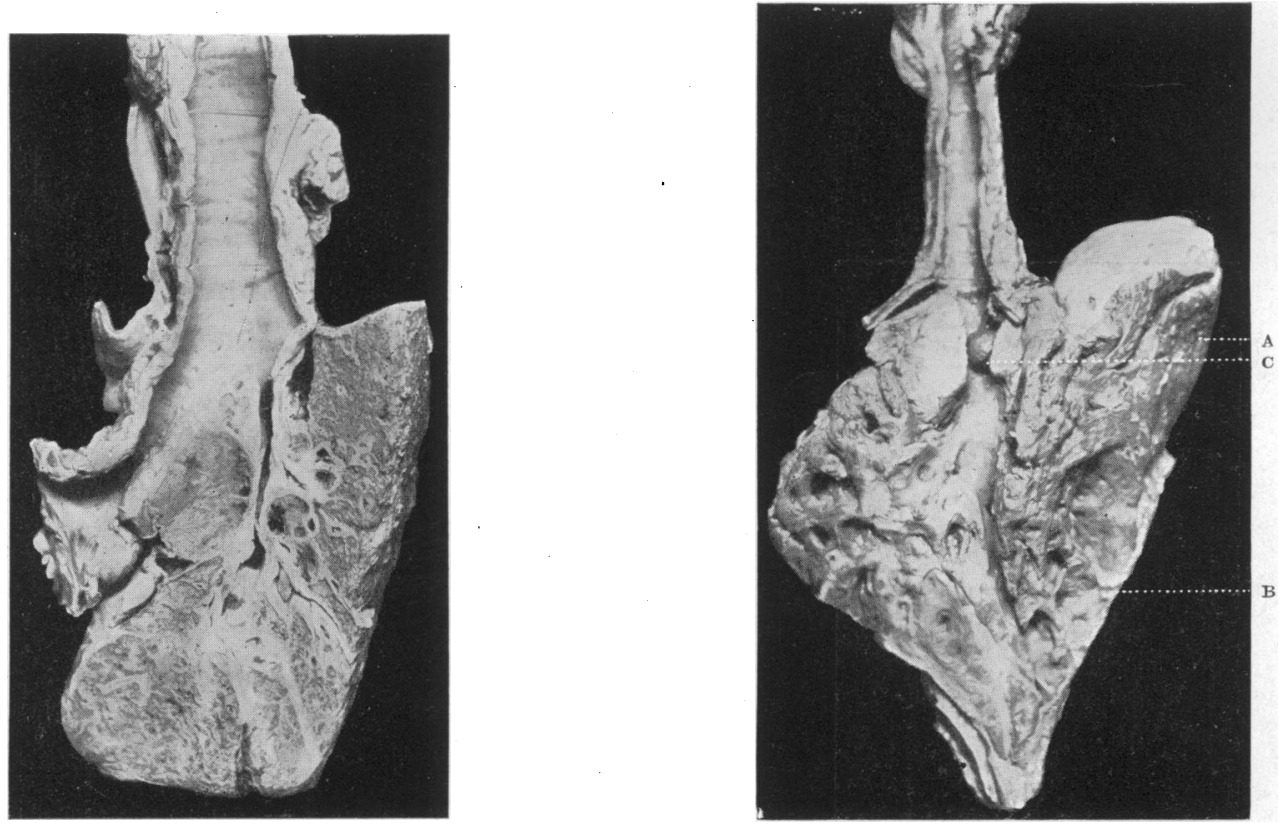

Fig. 13. 
bulged more than on the right; there were diminished tactile vocal fremitns and voice sonnds. The chest circumference wos 36 in. and the expansion $\frac{3}{4}$ in. The heart sounds were indistinct, but were best heard behind the sternum and to the right. Diagnosis: Growth or pneumothorax. The temperature oscillated between $102^{\circ}$ F. and normal while the patient was in the hospital. On April 26th, 1902, the chest was smaller, being only 34 in., and there was a slightly impaired note over the precordium. Fatal haemoptysis occurred.

Post mortem a saccular aneurysm was found opening into and compressing the left bronchus. There was a septic pneumonia of the left lower lobe, with flbrosis and bronohiectasis.

CASE v.-Aneurysm of the Descending Aorta Opening into the Left Bronchus.? Pneumothorax or Aneurysm.

The patient, a man aged 38 years, had dyspnoea and pair with impaired movement and absence of breath sonnds on the left side; there was a hyper-resonant note and the heart was displaced to the right. Oa September 20th, 1897, there was some dullness at the left base. Fatal haemoptysis occurred while the physician was preparing to explore. ? Pneumothorax or aneurysm.

Post mortem there was an aneurysm at the commencement of the descending aorta, which had opened into the left bronchus near the point of bifurcation. The lungs were mottled with blood that had been sucked in; the edges were emphysematous. The lower lobe was solid, mottled grey: odourless pus in the tubes.

CASE VI.-Aneurysm Compress. ing the Left Bronchus: Left Lung Over-distended, the Signs suggesting Pneumothorax.

The patient in this case had a well-formed but emphysematous chest, the left side being more bulky and larger than the right and not moving so well ; in fact, scarcely at all. No apex beat could be felt; there was 8 slight pulsation in the third right space $1 \frac{1}{2}$ in. from the edge of the sternum. There was a hyper-resonant note in was a hyper-resonant note in cardiac and the splenic dullcardiac and the splenic dullness. Bresth sounds were very faint at the apex; there were no tactile vocel fre mitus, no voice sounds, and no bruit d'sirsin. The cir cumference of the left chest was 18 in.; at the level of was 18 in.; at the level of the level of the left, $17 \frac{3}{4}$ in. There was no movement on the left. Diagnosis: Pneumothorax due probably to the rupture of a phthisical rupture of a phthisical was remittent. Later, the note at the left base was slightly impaired.

The following is a re maxkable instance in which the patient survived twenty months after the first severe haemorrhage from the erosion of the aneurysm into the bronchus, the opening being probably a valvalar one, which he was able to close by retracting his head and thus diminishing the antero-posterior dismeter of his chest.

CASE VII.-Aneurysm of the Aorta, one compressing the Left Bronchus, and another the Trachea: Recurrent Haemoptysis for Twenty Months before Death.

The patient, a man aged 50, under the care of Dr. Parry Jones of Derby, had four years ago dyspnoea on exertion, when an sneurysm was suspected; twenty months before death haemoptysis (1 pint) occurred; the blood came more rapidly when he leaned forwards, and was checked when he drew back his head. He also noticed that turning his head to the right reduced the volume of his right pulse. Gradually a slight pulsation with a diastolic jog developed beneath the left clavicle. There were diminution of bresth and voice sounds on the left side, but no dullness. There were four further attacks of haemoptysis amounting to several ounces during the next year, bat by reducing his fluid to $13 \mathrm{oz}$. and keeping quiet he kept them in abeyance.

Three dilatations were found in the ascending, transverse, and descending portions of the arch. The opening into the air 6 tube was closed up. There was no great amount of bronchiectasis. It is remarkable he should have sarvived the first ruptare for twenty months.

CASE VIII.-Saccular Aneurysm of the Descending Aorta which Compressed the Left Bronchus and the Oesophagus.

The patient, a man aged 49, under the care of Dr. Morgan of Seaford, had had pain for a year in the left chest and cough for three months. Recently there had been expectoration in the morning streaked with blood. He had dysphagia, liquid food frequently coming back again into his mouth after some little time if be swallowed. Dyspnoea ensued on exertion; there was defective movement on the left side, with distension of the veins on that side of the chest. There was resonance with deflcient breath sounds over the left side, and a very marked delay (almost one second) in the onset of inspiration, which was quite noticeable when a double stethoscope was used. There were deficient voice sounds and the tactile vocal fremitus note was very slightly impaired, if at all. In the skiagram (Fig. 9) a large saccular aneurysm can be seen near the origin of the descending aorta, pressing on the left bronchus and delaying the passage of some milk and bismuth he had just taken. The oesophagus can be seen distended above and the bismuth trickling past the obstruction. When he contracted the oesophagus some of the contents were returned into his mouth.

The features especially associated with the pressure of an aneurysm on a bronchus may be summed up as follows: 1. The left bronchus is involved six times as often as the right. 2 The right is very rarely eroded. 3. Resonance with silence. There are deficient or absent breath sounds over the left lung with a resonant or hyper. resonant lung. This does not necessarily indicate more than a partial occlusion of the bronchus, and occasionally in an early stage the left lung may be over-distended and be too transparent to $x$ rays. The condition has, then, to be diagnosed from pneumo. thorax. 4. With $x$ rays dilatation of the aortic arch can generally be detected, as the disease of the wall is generally multiple and diffuse. The local aneurysm often is best shown in a view in the half tarned position with the patient sitting up. The deficient and delayed move. ment of the lung, the altera. tion in its density, and the abnormal position and movement of the dia. phragm are usually obvious. Occasionally no local aneurysm nor yielding of the aorta can be detected. 5. Later, the development of an impaired note rather than complete dullness, with gradual development of bronchiectasis. It is remarkable how the amount of change which develops is always under-estimated owing to the breath sounds being absent or feeble. 6. Absence of plearitic effusion. 7. Retardation of the onset of inspiration on the affected side. 8. In nearly half the cases more or less haemoptysis. Pain with dyspnoea on exertion are very constant symptoms.

As soon as the mucous membrane ulcerates the liability of the contents of the bronchi to become freshly infecte $d$ is greatly increased, as the spot is very apt to become a niaus for organisms itself. Hence necrotic changes in the lung occur more often when the tube is alcerated than when it is only compressed, just as primary growths in the bronchus are especially associated with gangrene.

Malignant Disease (55 Cases).

The growth may originate (1) in the bronchus, (2) in the glands at the root of the lung, (3) it may be a secondary 
deposit in the glands at the root of the lung and grow into it along the bronchus, and (4) as an epithelioma of the oesophagus ultimately invading the bronchus.

1. Primary growth in a bronchus is rare (8); in 4 cases it started in the right and in an equal number in the left. The growth is generally a columnar.celled carcinomaat least four-fifths of cases of primary cancer of the lang start in the bronchial mucous membrane. Most of the cases came under observation for plearitic effasion, which not infrequently required tapping more than once. In half the cases gangrene of the lung developed. In some a fragment of growth was expectorated, and thereby its malignant nature determined. There are generally pain and pressure signs.

2. Growth in the glands (26 cases) half affecting each bronchus. Two were described as lymphadenoma, bat as they eroded the bronchus it is more probable that they also were sarcomatous.

3. Secondary deposits in the glands at the root of the lung (6 cases): the growth compressed the bronchus and invaded the lung.

4. Epithelioma of the oesophagus (16 cases). The two bronchi are invaded with equal frequency. In four they were only compressed; in the others the growth had fungated in. With epithelioms the pulmonary condition rapidly proves fatal, with a septic pneumonia, abscess formation, or gangrene. Bronchiectasis and fibrosis have not time to develop. The rapidly fatal changes are due to the infection with food from the communication with the oesophagus. The food is doubtless often squeezed in by the contraction of the oesophagas owing to the obstruction of its tabe bejond by growth. In one case a deposit in a gland led to compression of the lower branch of the left bronchus with the development of bronchiectasis bejond. A troublesome paroxysmal cough, pyrexia, and pain are the indications of the onset of trouble in the lang, to which foul expectoration is soon added.

The special features of malignant disease are the frequency with which pleuritic effusion and also gangrene develop (more than half). The effusion is an early sign, and both this and the collapse of the lung, as well as the growth itself, all give dullness which is often quite marked. It has been pointed out by writers that the physical signs given by the changes in the lung and the pleura are obvious at an early stage and tend to obscure the evidence of the growth itself. In many the pulmonary artery is also compressed and may be occluded, and this is much more frequently so than by an aneurysm; hence the rapid development of extensive patches of gangrene which may lead to the development of large cavities, often without fibroid thickening of the wall. In a small proportion fibroid changes in the lung are well marked; in others there has not been time for them to take place. Bronchiectasis is by no means always present, but only in one third.

The massive infiltration of the root of the lang occludes not infrequently the lymphatics and blood vessels as well as the bronchi; hence oedema of the pulmonary tissue tends to develop and the bronchi to become more rapidly overfall of secretion. Stridor is not infrequently present, especially on exertion, bat is most marked when the growth has also compressed the trachea.

CASE IX.-Squamous Epithelioma of the Root of the Lung with Destructive Disease of the Lung beyond. (Fig. 10.)

The patient was a man, aged 65 years, who for twenty months expectorated material of the colour of strawberries and cream at one time amounting to a pint a day. The only physical signs were deficient breath sounds over the left base.

Post mortem the left lower lobe of the lung was excavated ont into a cavity $4 \frac{1}{2}$ in. across, with flocculent necrotic walls, there were numerous dilaied bronchi in the rest of the lobe with fibrosis. The bronchus and pulmonary artery were compressed, being embedded in the mass of growth. The primary sest was not determined as the post-mortem examination was limited to the thorax.

This specimen is of interest as showing the early formation of a single large cavity from destructive changes from necrosis, and in this instance without any foul secondary putrefactive changes. It illustrates the fact that the physical signs of a large cavity over 4 in. across may be almost nil when there is stenosis of the bronchus, owing to the absence of any breath sonnds. Contrast it with the extensive fibrosis and the usual absence of large cavities which result when the pressure is due to an aneurysm.
As another example showing how a mass of sarcoma growing into the root of the lung associated with occlusion of the pulmonary artery tends to form large cavities, in addition to a general fibrosis of the lung with moderate dilatation of the tubes, the following may be quoted:

\section{CASE $x$}

The patient, a woman aged 38 years, died a few hours after admission. At the inspection the left lung was healthy. A section has been made of the right lung, with the mass of growth at its root. A rod has been passed through the much(1) palmonary artery exce branch was occluded. Almost the whole of the lower lobe was excavated out into a cavity. There were smaller cavities in the lower part of the upper and middle lobes with general dilatation of the tubes in a dense fibroid tissue. (Fig. 11.)

CASE XI.-Primary Cancer of Bronchus : Expectoration of a Nodule of Growth: Duration of Symptoms three and a half Years . Fibrosis with Bronchiectasis.

The patient, a man aged 40 years, first noticed some wheeziness in September, 1901, and during the year 1902 he became short of breath on exertion; he lost half a stone in weight; ther was an ounce of muco-purulent secretion daily, and on exertion or deep breathing there was some stridor. The wheeze or musical whistle with expiration was loudest when he lay on his left side. He had no pain. In Ootober there weredeficient breath sounds with a slight squesk, and deficient voice and taotile vocs fremitus over the left side, with dullness in front at the apex. There was similar deficiency in breath sounds at the apex; the base was fairly normal; the right oide was quite norms. With a skiagram there was a slight opacity at the left apex, bu less than is often met with in growth, although the evidence pointed in that direction. There was no evidence of aneurysm. He was subject to attacks of pyrexia with an increase in the expectoration. He continued to lose weight, and towards the end of the year there was a pleuritic rub. He had a few slight rigors. In December the dyspnoea had increased considerably, and he was very frequently sick unless very careful with his diet. A rough, blowing systolic bruit developed to the left and above the heart; the resonance became more impaired above, and the breathing indeterminate, with an increase in the voice sounds. The impules of the heart was pulled upwards and outwards. There wes pulsation over the affected area at the outwards. There w\&s pulsation over the affected area at the
left apex which apparently was transmitted from the heart and was not due to an aneurysm. The diaphragm was as high as the fifth rib in the axilla. During the year 1903 he was able to get about if he moved slowly. Expectoration was limited to half an ounce; it was slightly blood-stained, but never offensive. The amount of blood varied somewhat.

The patient continued fairly well until May, 1904, when he had an attack of pericarditis, which lasted for six weeks. In Decem ber, 1904, he coughed up a piece of tissue an inch long and three-eighths of an inch in diameter, which came away quite easily. with only a little haemorrbage. On microscopical examination this was found to be a portion of glandular car cinoma composed of tortuous columns of columnar cells ; there were also cells in alveoli which communicated with these columns. Another nodule was expectorated in the following March. On April 18th, 1905, I again saw him with Dr. Cock. burn of Ealing. The patient had got worse during the last six months, frequently expectorating as much as an ounce or two of blood. The dyspnoea had increased. He was practically confined to his bed. For a long time he was unable to lie on bis left side, and latterly only on his right side. There was pulaztion as high as the third space above the nipple, to the left of the heart; there were a noisy, wheezy stridor and noisy expectoration. We came to the conclusion that a nodule of the growth had fungated through, probably into the trachea, and it was a question whether there was not originally a foreign body in the left bronchus, which was the starting point of his trouble. He died the next day.

On post-mortem examination the right lung was found overdistended, but otherwise normal ; there was an adherent pericardium. There was a mass of growth at the root of the left lung, in which the bronchus and vessels were imbedded. No foreign body was found, the left lung wes extremely contracted. The upper lobe was reduced to a mass about 2 in. across and 7 in. long, riddled with small bronchiectasic cavities, while the lower lobe was converted into a very dense flbroid mass no bigger than the lung of a child of 6 , and was aleo riddled with cavities.

Compression by Inflamed Glands (12 Cases).

The cases were: Enlarged glands 7, suppurating and opening into bronchus 5. These cases occur mainly in infants in whom the glands are active, and the antero-posterior diameter of the thorax is so small that a mass of glands at the bifurcation of the trachea may lead to serious symptoms. but especially when they press on the trachea They less often compress the bronchi seriouely, and this generally only occurs when there are enlarged glands on each side of the bronchus, which accounts for the comparatively fow cases in which enlarged caseous glands give rise to pressure symptoms. The cases of pressure on the trachea are apt to be looked upo 
due to laryngeal diphtheria, but the absence of movement of the larynx is of diagnostic importance. Their enlargement may be made out by dullness internal to one sceppla, by the opacity shown by $x$ rays, by the absence of breath sounds on one side, and by a venous hum over the sternum on retracting the head, although I have only been able to elicit this sign three or four times.

When a suppurating gland breaks into a bronchus the child has severe dyspnoes with violent paroxysms of cough, and may bring up some puralent secretion, while there is soon an active development in the lung beyond of fresh physical signs. When in a child there are evidences that a bronchus is compressed, it is tar more likely to bo due to an enlarged caseous gland than to a foreign body, unless there is a definite history of sudden onset of symptoms after swallowing some. thing Most of the cases due to caseous glands are complicated with phthisis; less than half of them are diagnosed, but $x$ rays make it much easier to do so now than formerly.

In 3 cases abscesses opened into a bronchus: (1) em. pjema, right side; (2) suppurating bronchial glands secondary to suppurative pylephlebitis; and (3) abscess communicating with the oesophagus and gangrenous cavity in the lung.

CASE XIr.-Compression of Trachea and Right Bronchus by Enlarged Caseous Gland.

A child, aged 2 years, was admitted to hospital in 1910 with dyspnoes and stridor, which was supposed to be due to laryngeal diphtheria. On examination it was found that there were defoient breath sounds over the right side, with impoired resonance. The larynx did not move with respiration, and compression of the root of the right lung by caseons glands was compression of the root of the right lung by caseous glands was diagnosed. The ohild died a few hours later. A large caseous gland compressed the trachea in front, just above the bifarcathe right lang was collapsed and airless; the left lung was normal. (Fig. 12.)

Disated Left Auriche.

A cause of pressure sufficient sometimes to cause physical signs during life, but rarely to present much evidence post mortem, is a dilated left auriole due to mitral stenosis, to which attention was directed many years ago by Dr. Wilkinson King.

Case XIII.-Pressure on Left Bronchus by Dilated Left Auricle.

In 1888 a woman, aged 50 years, was seen suffering from mitral stenosis with a greatly dilated left auricle. At the inspection there was also a softening ante-mortem clot in the appendix. The left base was airless and sank in water; it could be inflated less than the right one, which was also oedematous and engorged. Both were deficient in air. The dilsted left auricle markedly compressed the left bronchus.

Fibrods Bronchionitis dof to Irritant Gasks.

Inhalation of irritant gases is a well.known cause of intense dyspnoes and bronchitis, not infrequently fatal, with a greatly over-distended lung, of which we have had examples from time to time. Fraenkel has shown that this condition may be due to an acute fibrous obliterating bronchiolitis, which may develop within a fortnight. He has recorded cases after inhalation of the fumes of chlorine, of cow hair and lime dust, and after calcium chloride dust. A man after inhaling chlorine had intense dyspnoea, which passed off but returned next day, when he was cyanosed, with an extremely distended lang and fine crepitations. The condition again cleared up, to return again after a week, when he died. Widespread fibrous peribronchial inflammation was fonnd round the smaller bronchioles, with necrosis of the lining epithelium producing constriction of the tubes with dilatation beyond. Schmorles has described a similar condition in the bronchopneumonia of measles, with obliteration of the bronchioles The ingravescent cyanosis with dyspnoea and a rapid and great increase in the size of the lung are the essential points, especially when there has been exposure to irritant gases.

\section{Stranosis of the Bronchi from Syphilis}

Out of 7 cases, 2 were due to gummata pressing on a bronchus. The way in which the tubes dilate under violent inspiratory efforts with bronchial obstruction is well shown in a case (No. xIv) of a man, aged 64 years, where a gumma pressed on the upper division of the right bronchus. The upper and middle lobes were over.distended; the lower lobe was airless from compression with five pints of fluid. The illness was rapidly fatal. The second (No. xv) was a chronic case with a gumma compressing the superior cava and the right bronchus; the bronchi beyond were dilated up to their extremity, and their walls were thickened; the lang was solid. There was extensive plearitic effusion into the left side secondary to the pressure on the cava.

There were 5 cases of cicatricial stenosis of the bronchus secondary to syphilitic ulceration, and the patients were all under the age of 40 . In 2 the larynx was also involved, in 4 the trachea, and in 4 there was bronchiectasis. Stridor is generally present, bat often is independent of the bronchial lesion. There are generally other signs of syphilis present, so that an accurate diagnosis can be made in the majority of cases.

\section{Case XVI.}

The patient was a man, aged 38 years; he was admitted with extreme laryngeal stridor and fixed cords due to laryngea] paralysis requiring tracheotomy. Post mortem the left lower lobe was collapsed. There was syphilitic stenosis of the right bronchus, with scars on the traches, flbroid right lung, with dense gummatous fibrous mass involving the root of the lung and the vagus. In spite of the vagns being involved, there was no degtrugive suggested that the destructive lung disease associated with aneurysm was due to implication of the vagus. (Fig. 13.)

\section{Foreign Bodies.}

The result of the introduction of a foreign body into a bronchus depends upon whether the bronchus is partially or completely occluded, on the vigour of respiration, and on whether the body is an organic one which will readily patrefy.

Oar knowledge of the changes which result largely depend on the experiments of Lichtheim in 1878, who introduced laminaria tents into the bronchi of rabbits, and also in others removed portions of the third and fourth left ribs, ligatured the bronchus, and studied the results. He showed that when the plug completely occluded the bronchus the lung quickly collapsed and became airless. There was at once an intense dyspnoea which gradually quieted down. In many cases the animals died within twenty.four hours with pneumothorax of the opposite side from raptare of an enormously over-distended lang; in others the over-distension of the sound lung had stretched the capillaries and made them useless, equally producing a fatal result. Pneumothorax from this cause does not occur in human beings. The affected lung beyond the obstruction was of a dull brown-red colour, with the consistency of muscle. With early death the bronchi were empty, bat became filled with a thick white mucoid secretion whenever the animal did not die too soon. When he ligatured the bronchus alone the same result was produced.

He found that when the animal was made to breathe oxygen absorption was much quicker, in some cases being under an hour; $\mathrm{CO}_{2}$ absorption was less rapid, but much more so than when it breathed air. When the pulmonary artery was also ligatured absorption was much delayed showing that the gases were absorbed by the blood circulating in the lang.

When the chest was merely opened and the lung exposed to the air atelectasis took place quickly, but did not if the palmonary artery was ligatured. This opening of the chest vitiates many of his results, as it prevented any vigorous respiratory movements from taking place. This was well shown by the fact that when the bronchas was ligatured the opposite lung did not become overdistended to the extent it did when the bronchus was blocked by a foreign body. When the hilum of the lung, including the pulmonary artery, was ligatured there was generally no infarct, because there had been no suction of the blood owing to the absence of the opening up of the alveoli with inspiration. This affords the explanation of the absence of infarcts in cases of growth at the root of the lung and of aneurysm in which the pulmonary artery had been occluded by pressure. When the animal survived some weeks the lang was fibroid and converted into a sac of dilated tubes, presenting an appearance similar to that of a calculous pyelonephritic kidney.

Partial obstruction of the bronchi has not been thoroughly stadied experimentally, and we have still much to learn 
the presence of expectoration in amount shows that this is the more usual condition which results from the presence of a foreign body in a bronchus, and I have little doubt that in some cases thelung at first becomes over.distended, and is not always airless and collapsed.

Schuller has shown that it is possible to introduce clean food into the bronchi of rabbits, and if it can disintegrate it will disappear with no change in the lung beyond that of catarrh ; when it cannot, fibroid changes with bronchiectasis result. When dirt, however, was mixed with the food gangrene or septic pneumonia resulted.

There have been the following cases: (1) Head of barley grass in left bronchus 129 days ; (2) pork in right bronchus possibly for six months; (3) wooden top of toy in left bronchus; (4) pea in left bronchus; (5) feather after tracheotomy in right bronchus, but not cause of death; (6) pipe stem in bronchus after fatal fall down ladder (not cause of death); (7) newspaper in trachea, introduced intentionally; and (8) sponges in trachea, introduced intentionally.

The following case presents many very remarkable features. The boy swallowed a head of barley grass during a paroxysm of coughing, and this passed into his left bronchus, where it remained 129 days. He developed within two days after the entrance of the body an acute pneamonia which became gangrenous, and he had an extremely prolonged dangerous illness. Acid-fast bacilli were found on one occasion in the sputum, and were assumed to be tubercle bacilli, but he made an excellent recovery as soon as he expectorated the piece of grabs. He never reacted specifically to tuber. culin. He has maintained perfect health for the five years since, and is now strong and well.

It is very rare for any one to make such an excellent recovery after such extensive mischief in the lung, and it is suggested that the acid.fast bacilli came from the grass, as these grasses are said to contain them.

CASE XVII.-Ear of Barley Grass in the Left Bronchus for 729 Days : Gangrene of the Lung: Complete Recovery.

A boy aged 12 years, while recovering from an attack of whooping-cough, was playing with a head of grass in his mouth, when he was seized with an attack of coughing and the piece of grass disappeared. He tried in vain to make him. self sick. On the next day the temperature was $102.8^{\circ}$, and on July $25 \mathrm{th}-$ the following day-Dr. J. E. G. Calverley of Folkestone, under whose care he was, found that the temperatur was $105.2^{\circ}$, with a palse of 100 . There was pain in the epigastrium. The entry of air at the left apex in front wa deficient. On the 28th there was diminished entry over the same area, with diminished movement but a hyper-resonant note. There was tracheal wheezing, conducted over the whole chest as rhonchi. The temperature, respiration, and pulse remained high, and on the 30 th the boy had consolidation at the left apex down to the third rib, with bronchial breathing and pectoriloquy. The larynx was found to b normal. On August lst there was profuse epistaxis, with a tympanitic note at the left apex in front. and down to the level of the fourth rib in the axilla. The entry of air remained deflcient at the left apex. He became ansemic from recurrent epistaxis. He then passed under the oare Dr. R. B. Wrightson at Aldeburgh. The temperature gradually dropped to $99^{\circ}$, and the boy was able to get about. The sputum at first was frothy, but later became abundant and mucopuralent, and was said to contain tubercle bacilli. In the middl of September his temperature ran up to $104^{\circ}$ and he developed signs of consolidation at the left bsse. In the upper lobe there was dullness at the apex with signs of a cavity in tront in the second and third spaces. There was a marked oscillation of the temperature with very foul bresth indicative of gan grene. He was extremely ill for a long time with a very feeble pulse. He took creosote regularly and was well narsed in the open air, so that gradually he recovered his health. No tubercle bacilli could be again detected, and at the end of October he had gained a stone in weight. The sputum was reduced to $\frac{1}{2} \mathrm{Oz}$. in amount daily, and was no longer fonl. On November 30th, 129 days after swallowing the grass, he had a fit of coughing, and brought up a head of barley grass $1_{4}$ in. long from the left bronchus. The long awns had broken of from decomposition, and so it was able to pass out again back wards, which had been quite impossible so long as they were intact. There was a gradual retrocession of the signs bu there remained at the apex a deficient resonance, with indeterminate breathing and increased voice sounds; a few moist sounds persisted at the lower part of the lung for some time. In December the opsonic index for tubercle was found to be 0.6 and 0.65 on two occasions. An attempt was made to see whether any acid-fast bacilli could be cultivated from the piece of grass, but none could be found, although many other organisms were present.

Fig. 14 (Case XvII) shows a pea wedged in the lower bronchus on the right side. The upper part of the lung is healthy, bat the rest of the lang is densely fibroid and riddled with intercommunicating cavities. The patient was a boy, aged 3 years, with cough and vomiting. He died with empyema and cerebral abscesses a month later.

CASE Xìx.-Piece of Pork in Right Bronchus : Bronchiectasis : Septic Pneumonia.

In 1888 a man, aged 60 years, was admitted. For six months there had been wasting, and for two weeks foul breath. For two days there had been deflcient movement of the lung on the right side, pleural rub in the axilla and base, deficient air entry, râles, with amphoric breathing over the middle lobe.

At the inspection the right lung was fibroid with general bronchiectasis of the main bronchi. Low down was found a piece of pork $\times \frac{3}{3}$ in. There were cavities in the lower lobe. There was acute pneumonia at the lower part of the upper lobe with oedema of the left lung. Had the pork been there for six months?

CASE XX.-Piece of Wool in Left Bronchus: Bronchiectasis of Both Lungs.

In 1905 a femsle child, aged 16 months, was seen. She was well until five weeks before admittance, when she had a cough and dyspnoea. The right lung was resonent on the anterior part in front, but impaired behind. There were crackling râles, ronchial breathing, and pectoriloquy behind.

At the inspection there was advanced fibrosis with bronchiectasis of the right lower, the right middle, and the left lower portions, with a mass of dilated tubes in the midst of the parts of the lang which were flbroid. The two left upper lobes were distended; there was recent bronchopneumonis. In the left bronchus, just beyond the point of bifurcation, there was a smooth piece of wood broken off a toy. It was doubted at the necropey whether the piece of wood had caused the bronchiectasis, because it was found in the left bronchus and the bronchiectasis was also on the right side, but probably at an earlier stage it was in the right bronchus, and had produced changes on that side and been displaced to the left later.

Although many cases of foreign bodies in the bronchi have been recorded, in but very few has an accurate note been made of the physical signs in the lung in an early stage of the illness. The body generally passes into the right bronchus because it is more vertical and is also slightly larger. The changes are unilateral, serious, and progressive.

The following are the most important evidences suggestive of a foreign body in a bronchus, and in any such case a bronchoscope should be passed in order that the con. dition of the tubes may be determined, and a positive opinion formed: (1) A most important factor in diagnosis, and one which until we had $x$ rays was absolutely essential, is the history of swallowing something immediately before the onset of an aoute attack of severe dyspnoea and cough. (2) Not infrequently a whistling or wheezing sound which the patient can localize to one side, varying in quality if the object is not fxed in the bronchus. (3) Great distress, with not infrequently a constricting pain behind the sternum, made worse by movement. (4) Dyspnoea, with varying exacerbations, often intense and made worse by cough, but it may be elicited only by exertion. After a time there may be no distress. (5) Absent or, rarely, very noisy breath sounds, with some slight diminution of voice and tactile vocal fremitus limited to one side of the chest. (6) At first resonance on the affected side, soon consolidation with dullness, and, after a time, the signs of cavities, and the simulation of phthisis; query occasionally hyper-resonance. The physical signs sometimes vary from time to time. (7) With $x$ rays, the defective movement of the diaphragm and of the thorax, the alteration in the density of the lnng, and not infrequently the outline of the foreign body itself, may be clearly made out. (8) Delay in the commencement of inspiration as compared with that on the other side. (9) Defective movement with consequent dimination in the size of the affected side. (10) Violent paroxysmal persistent cough, which is apparently most marked when the object is at the bifurcation, as the sensibility of the mucous membrane is greatest here, as can be noticed when passing a bronchoscope. (11) Early pyrexia, which later becomes hectic, associated with chills. (12) After a short time an expec. toration more or less "profuse, purulent, often bloody, and later often fetid. (13) In some there are nausea and vomiting, which may be very troublesome. (14) Pneu. monia often develops in forty-eight hours; this may be septic and may be followed by gangrene.

[We are indebted to Messrs. Bale, Sons and Danielsson for the loan of the block of the portrait of Dr. Bradshaw which appears on p. 1845.] 